\title{
Architecture based Comparison of Semantic Web Service Composition Processes
}

\author{
Aditya Khamparia \\ Research Scholar \\ School of Computer Science and Engineering \\ Lovely Professional University \\ Phagwara, Punjab
}

\author{
Babita Pandey \\ Associate Professor \\ School of Computer Applications \\ Lovely Professional University \\ Phagwara, Punjab
}

\begin{abstract}
Semantic web services development become rapidly increased as dynamic changes are occurred. Various approaches are adopted to develop composite service systematically. This paper aims to make development process easier by classifying the literature on web services composition based approaches like selection, discovery, orchestration, choreography, mediation, automatic composition to facilitate the end to end semantic web service composition easier. Applying semantics in web process cycle helps to address critical issues in reuse, integration and scalability. In order to find best approach, various composition approaches on these requirements were evaluated and suggestions were provided on what approach can be used in which scenario to achieve best results.
\end{abstract}

\section{Keywords}

Semantic web service, Service Composition approaches, Selection, Discovery, Orchestration, Choreography.

\section{INTRODUCTION}

Semantic web is an extension of current web, in which information is given well defined meaning, better enabling computer and people to work in cooperation [1]. The objective of research around semantic web service is to facilitate automatic handling of web services. Semantic web transforms the web into repository of computer readable data, while web services provide tool for automatic reuse of that data. Sometimes single service component unable to satisfy user needs then some mechanisms like discovery [4], selection [18], mediation [12], matchmaking etc. are used for finding service component and semantic composition helps to aggregate the component of various services according to tasks. In previous work we have made a survey on different approaches of semantic web services [18]. The main objective of this paper is to discuss some existing composition techniques like Workflow based, Artificial Planning, Context based, Agent based, Ontology based, Orchestration and Choreography to solve semantic web composition problem with their attributes. In addition, we have also classified and compared different web service composition methods. Apart from introduction part, section 2 deals with various composition based method for semantic web service, section 3 covers framework of service composition methods, section 4 covers classification and comparison among several approaches and conclusion in section 5 .

\section{EXISTING APPROACHES FOR WEB SERVICES COMPOSITION}

Various software programs are available to facilitate automatic composition of services. Such programs enable user to specify composition of programs to perform some varied tasks. In this section we will focus on several approaches like workflow based, AI Planning approach, Orchestration, Choreography, Mediation, Ontology based, Agent based, Discovery, Selection for semantic web service composition.

\subsection{Workflow based SWS Composition approach}

A workflow is abstraction of a business process. It comprises of tasks, dependencies among tasks, rules and participants. Task represent a software system in which task flow from one web services to another service and performed appropriate functionality. OWL-S process model [2] is work flow driven model for web service composition. This model uses DAML based match maker. Workflow is composed with help of composite and atomic processes. Various compositions constructs like conditional and looping constructs are used to perform automated composition. Knowledge based approaches used domain knowledge for composition and selection of services and also used WSDL [9] to accompanied the description and execute the workflow. Framework must comprise of knowledge representations and ontology, web services modules, semantic environment. Input request matching also uses work flow pattern, this matching process is used to find services available for clients input request and output matching is done with last service in work flow.

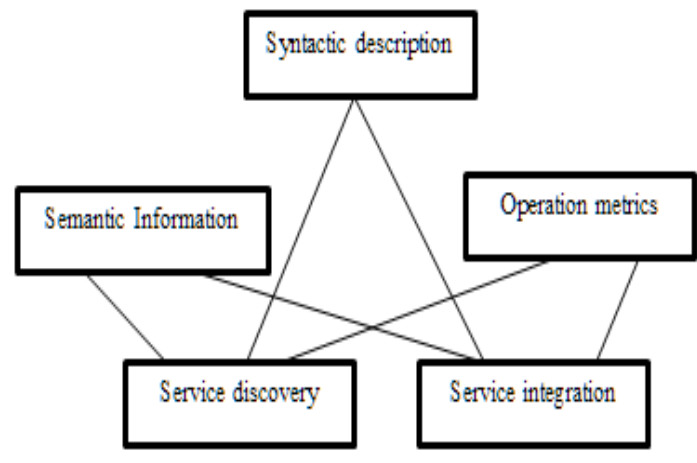

Fig 1: Workflow based Service Composition

\subsection{AI Planning based approaches}

AI Planning is fully automated semantic based approach; it focuses on goal driven architecture for automated problem solving. In AI Planning on the client side user specifies his objective and planning algorithm takes the objective of client as goal and produces a plan for goal resolution process. In this plan construction takes place repetitively to achieve static, finite, automated environment. OWL-S is used in AI planning 
based approaches. Precondition and effect properties of service in OWL-S indicate the state change during implementation of services. Various AI planning based model developed like Zeng et al. [3] proposed rule inference engine in which services are annotated with QoS features. Sirin et al. [4] Proposed hierarchical task network planning which supports non deterministic services and observability of service effects. Berardi at al. [5] discussed automatic synthesis of finite state machines to support real world, external services. Functional compositions based planning model [6] uses Casual Link Matrix (CLM) to composite link between various services and store these casual links. Links shows dependency between input and output parameters of different web services.

\subsection{Service orchestration \& choreography}

Orchestration refers to an executable process and choreography tracks message sequence between parties and source. In orchestration the involved web service are under the control of single end point central process. This process coordinates the execution of different operations on web service participating in orchestra. BPEL is an orchestration language with an XML based syntax supporting specification of process that involves operations provided by web services. Choreography doesn't depend on central coordinator. Each web service that participates in choreography has to know exactly when to become active and with whom to interoperate. It must be conscious of business process, operations to execute, messages to exchange, as well as timing of message exchange. WS-CDL is a recommendation language in area of service composition.

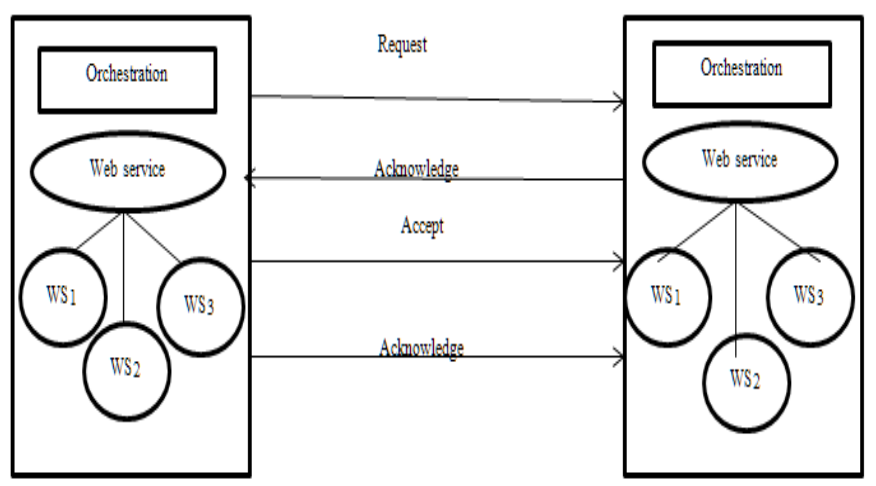

Fig 2: Service orchestration and Choreography

\subsection{Ontology based composition approach}

Ontology describes the knowledge representation about specific domain. Relationship among classes and objects is used for semantic composition of services in ontology domain. Stack of ontology based model [7] uses ODE reasoning. In this services are graphically designed and then instance is created. Design of service ontology is checked and instance of ontology are translated into OWL-S specification. It helps in producing graphical design of services.

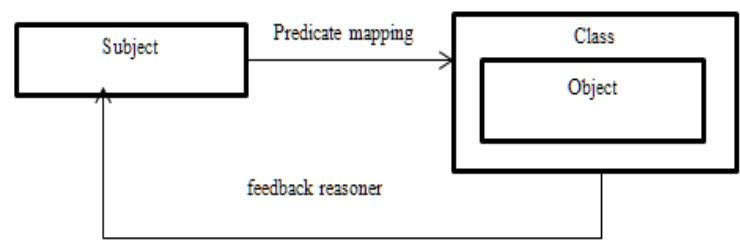

Fig 3: Ontology relation

\subsection{Semantic service mediation}

Semantic level mediation is a mediator between concurrent semantic representations of services, to allow semantic web service matchmaking algorithms to compare capabilities of distinct semantic web service. It requires identifying similarity across distinct web service representations. Manual one to one and semiautomatic mapping are governed in mediation process level. They used mediation space as a mediator approach. It computes similarity to identify most appropriate semantic web service for given request.

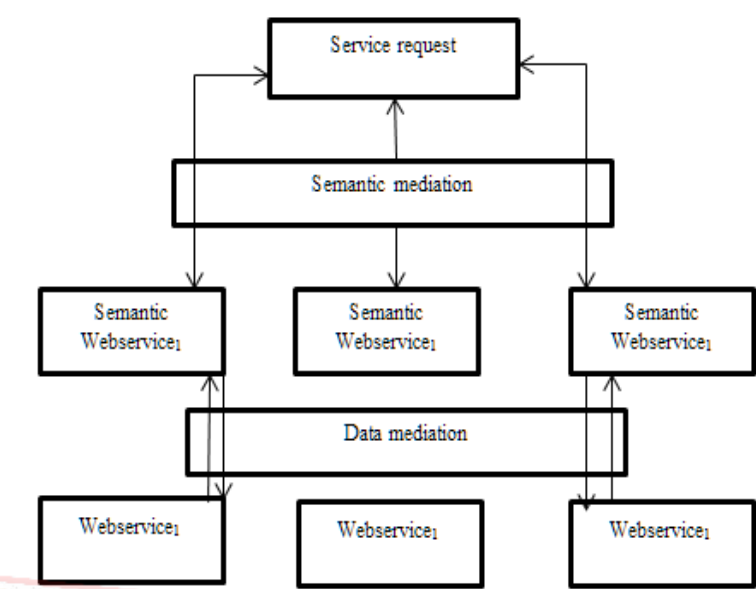

Fig 4: Service mediation

\subsection{Agent based approach for composition}

Reusable software components are known as agents. Main capability of agent is to coordinate, communicate and collaboration. Multi agents are required to achieve composite service composition. Discovery, selection and composition processes divides complex tasks to small modules and then select suitable service provider agent for specific tasks after decomposition. Various languages like DAML, RDF and $\mathrm{XML}$ are used to create agents. Various ontological tools like protégé, OWDS, are proposed to build such agents. Deliberate agent architecture such as BDI [8] called belief, desire and intention used to make composition more intelligent. Learning 
feedbacks techniques are used to improve agent intelligence to complete desired tasks.

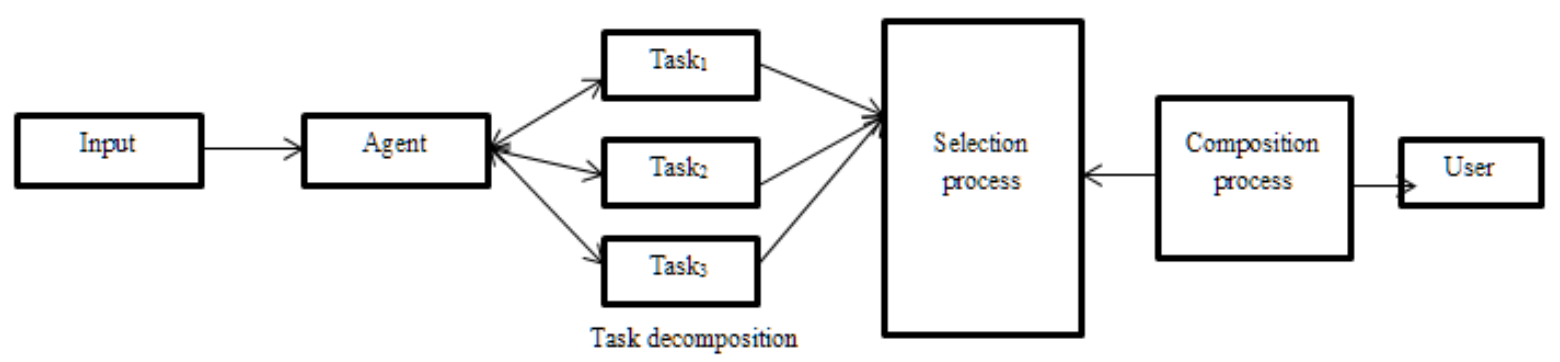

Fig 5: Agent based composition approach

\section{FRAMEWORK OF SERVICE COMPOSITION METHOD}

specification, planning, validation, discovery, execution and monitoring.

Service composition life cycle involves following phases to develop end to end service composition. It includes

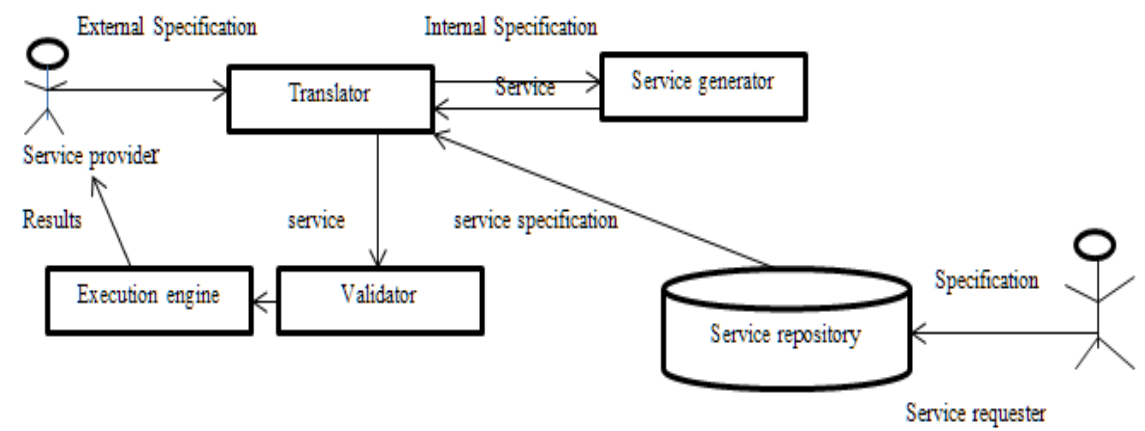

Fig 6: Framework of service composition

Service provider propose web services for use, service requester consume information or service offered by service provider. Translator converts or translates external language used by participants and internal languages used by service generator. If more than one plan found validator validates and evaluates all plans and proposes the best plan for execution. Execution engine executes the plan and return the result to service provider.

\section{CLASSIFICATION AND COMPARISON OF VARIOUS SEMANTIC WEB SERVICE COMPOSITION TECHNIQUES}

Various semantic web service composition techniques or approaches are classified as shown in figure name. Service classification is based on six categories user defined, service selection, automatic, discovery, mediation and matchmaking. Main concern here is to include all static and dynamic automated approaches like orchestration, choreography, discoveryetc.

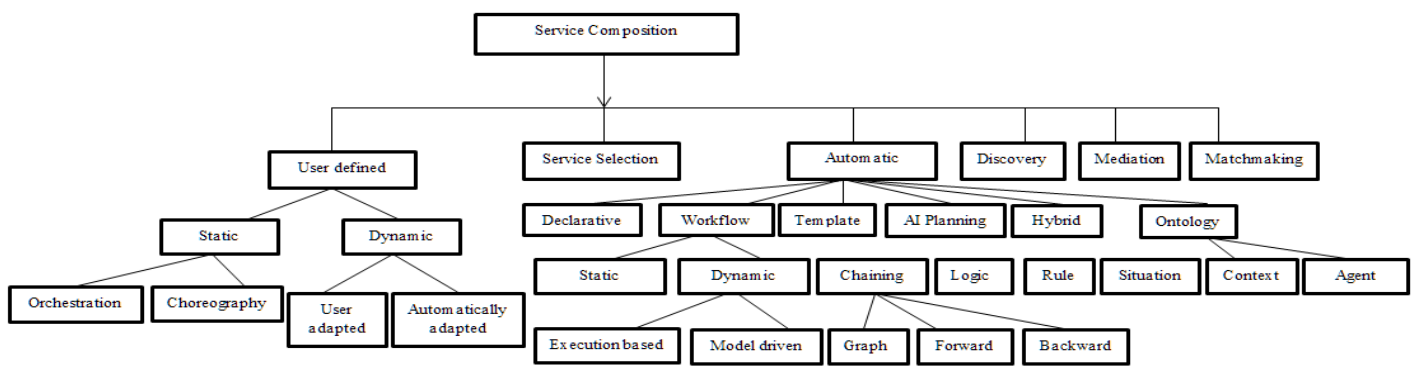

Fig 7: Classification of service composition approaches

A tabular comparison for service composition approaches mentioned on the basis of approach used, feature supported or comparison approach, tools used, language and interface. 
Table 1: Tabular comparison of AI Planning approaches

\begin{tabular}{|c|c|c|c|c|c|}
\hline Author & Method name & $\begin{array}{c}\text { Comparison } \\
\text { process }\end{array}$ & Tools used & Language used & Interface \\
\hline Zeng et al. [ 2] & $\begin{array}{l}\text { Rule inference } \\
\text { engine }\end{array}$ & $\begin{array}{l}\text { Services are } \\
\text { annotated with } \\
\text { QoS and cost } \\
\text { features }\end{array}$ & JADE & JAVA & GUI \\
\hline Pistore et al.[3 ] & $\begin{array}{l}\text { Model checking } \\
\text { planner }\end{array}$ & $\begin{array}{c}\text { Non } \\
\text { deterministic } \\
\text { service and } \\
\text { partial } \\
\text { observation of } \\
\text { service effects }\end{array}$ & MBP & BPEL4WS & GUI \\
\hline Sirin et al. [4] & $\begin{array}{l}\text { Hierarchical task } \\
\text { network planning }\end{array}$ & $\begin{array}{c}\text { Hierarchical } \\
\text { decomposition of } \\
\text { tasks into atomic- } \\
\text { invokable service }\end{array}$ & No specific & OWL-S & Not specific \\
\hline Zixin et al. [5] & Automatic & $\begin{array}{l}\text { Message is } \\
\text { converted into } \\
\text { BPEL format to } \\
\text { select the best } \\
\text { element, } \\
\text { executable } \\
\text { control flow } \\
\text { performed }\end{array}$ & Jena & JAVA, BPEL & GUI \\
\hline Freddy et al.[6 ] & $\begin{array}{l}\text { Functionality } \\
\text { based }\end{array}$ & $\begin{array}{l}\text { Semantically } \\
\text { ordered and } \\
\text { linked plan on } \\
\text { basis of casual } \\
\text { link for web } \\
\text { services }\end{array}$ & CLM & OWL-S & No interface \\
\hline
\end{tabular}

Table 2: Tabular comparison of Orchestration and Choreography approaches

\begin{tabular}{|c|l|l|l|l|l|}
\hline Author & Method name & \multicolumn{1}{|c|}{$\begin{array}{c}\text { Comparison } \\
\text { process }\end{array}$} & Tools used & Language & Interface \\
\hline Jaydev \& & Orc & $\begin{array}{l}\text { Orc supports a } \\
\text { structured model } \\
\text { of concurrent and } \\
\text { distributed } \\
\text { programming }\end{array}$ & Orc tool & $\begin{array}{l}\text { RDF-S, JAVA, } \\
\text { BPEL }\end{array}$ & GUI \\
\hline $\begin{array}{c}\text { Sung -Shik et al. } \\
\text { [ 8] }\end{array}$ & Reo based & $\begin{array}{l}\text { Input as } \\
\text { description of } \\
\text { service, WSDL } \\
\text { interface to } \\
\text { generate code }\end{array}$ & Reo Map & Reo, JAVA & GUI \\
\hline
\end{tabular}


Table 3: Tabular comparison of Workflow based compositions methods

\begin{tabular}{|c|c|l|l|l|l|}
\hline Author & Method name & \multicolumn{1}{|c|}{$\begin{array}{c}\text { Comparison } \\
\text { process }\end{array}$} & Tools used & Language & Interface \\
\hline BROGI et al. [ 9] & YAWL & $\begin{array}{l}\text { Simulation and } \\
\text { analysis of } \\
\text { behavior of P2P } \\
\text { peers and services }\end{array}$ & Not specific & SMoL, BPEL & GUI \\
\hline Rongen et al.[10] & $\begin{array}{c}\text { Knowledge based } \\
\text { system }\end{array}$ & $\begin{array}{l}\text { Web service } \\
\text { creation using } \\
\text { knowledge base } \\
\text { and ontology for } \\
\text { composition }\end{array}$ & FaCT & DAML-S & WCI- GUI \\
\hline Javier Rios et al. & Magallenes & $\begin{array}{l}\text { Enables web } \\
\text { service discovery } \\
\text { and automatic } \\
\text { work flow } \\
\text { composition }\end{array}$ & Magallenes tool & RDF-S & GUI \\
\hline
\end{tabular}

Table 4: Tabular comparison of semantic level mediation service

\begin{tabular}{|c|c|l|l|l|l|}
\hline Author & Method name & $\begin{array}{c}\text { Comparison } \\
\text { process }\end{array}$ & Tools used & Language & Interface \\
\hline $\begin{array}{c}\text { Stefan Dietze et al. } \\
{[12]}\end{array}$ & Mediation & $\begin{array}{l}\text { Using mediation } \\
\text { spaces to identify } \\
\text { most appropriate } \\
\text { web service }\end{array}$ & MS & OWL-S & GUI \\
\hline
\end{tabular}

Table 5: Tabular comparison of agent based semantic web service composition

\begin{tabular}{|c|c|c|c|c|c|}
\hline Author & Method name & $\begin{array}{c}\text { Comparison } \\
\text { process }\end{array}$ & Tools used & Language & Interface \\
\hline $\begin{array}{c}\text { Ermolayev et al. } \\
\text { [13] }\end{array}$ & $\begin{array}{l}\text { Behavior agent } \\
\text { (BDI) }\end{array}$ & $\begin{array}{l}\text { Behavior of web } \\
\text { pages and agents } \\
\text { are specified using } \\
\text { behavior oriented } \\
\text { design }\end{array}$ & $\begin{array}{c}\text { XML } \\
\text { conventions }\end{array}$ & DAML-S & No specific \\
\hline $\begin{array}{c}\text { Kumar and Mishra } \\
{[14]}\end{array}$ & Multi agent & $\begin{array}{c}\text { Handling } \\
\text { negotiation } \\
\text { condition and } \\
\text { handling request }\end{array}$ & $\begin{array}{l}\text { Multi agent based } \\
\text { composition tool }\end{array}$ & OWL, RDF & GUI \\
\hline $\begin{array}{c}\text { Kungas and } \\
\text { Matskin [ 15] }\end{array}$ & $\begin{array}{l}\text { P2P based Mas } \\
\text { system }\end{array}$ & $\begin{array}{c}\text { Take available } \\
\text { service as input } \\
\text { and transfer them } \\
\text { in logic formula } \\
\text { by applying } \\
\text { deduction }\end{array}$ & $\begin{array}{l}\text { Distributed } \\
\text { Symbolic } \\
\text { Reasoning }\end{array}$ & OWL-S & GUI \\
\hline
\end{tabular}

\section{CONCLUSIONS}

The motivation behind this paper is to study the various researches carried out in semantic web services. This paper puts an effort in comprehensive study on Web service composition and related techniques or approaches. This paper mainly focus towards popular automated composition approaches like AI planning to automate plan for execution of specific service, Work flow approach to find out flow from input to output on work items, orchestration and choreography to identify business processes and service interactions, 
ontology among classes objects and their relationships and agent based technology to mediate agents and their problem solving approach. As growing need of semantic web services there is need to provide flexible, dynamic, intelligent solutions to remove limitations of AI planning approaches and focused more on agent based approach to facilitate real world applications.

\section{REFERENCES}

[1] Rao, J. and Su, X. 2004 "A survey of Automated Web Service Composition Methods", In Proc. Of $1^{\text {st }}$ International Workshop of Semantic Web Service and Process Composition.

[2] Huiyuan Zheng, Jian Yang, QoS. 2010 "Analysis and Service Selection for Composite Services", in the Proceedings of International Conference on Services Computing.

[3] Piergiorgio Bertoli, Alessandro Cimatti, Marco Pistore and Paolo Traverso. 2003 "A Framework for Planning with Extended Goals under Partial Observability", in Proceedings of ICAPS-03.

[4] Wu, D., Sirin, E., Hendler, J., Nau, D., and Parsia, B. 2003 "Automatic Web Services Composition Using SHOP2", in Twelfth World Wide Web Conference.

[5] Zixin Wu, K Gomadam, Amit P. Sheth. 2009 " A miller automated semantic web service composition" WWW.cs.uga.edu/ jam/papers/zLSDIpapers/zixin.doc.

[6] Freddy Lecue and Alain Leger. 2005 "A formal model for semantic web service composition, $5^{\text {th }}$ international semantic web conference, Athens, Georgia, pp. 86-95.

[7] Jayadev Mishra and William cook. 2006 "Computation orchestration- basis for wide area computing", Journal of software system model, Springer-Verlag, pp. 83-110.

[8]. Sung- Shik, Francesco Santini et al. 2013 "Orchestrating web services using Reo", SOCA Springer-Verlag.

[9] Antonio BROGI, Razvan POPESCU 2008 "Workflow based semantics for peer to peer specifications", Journal of front computer science, Springer-Verlag, pp. 398-412.
[10]. Erik Rongen, Peter Sloot et al. 2005 "An automatic Composition and Selection of Semantic Web Services", LNCS, Springer Berlin, pp. 184-192.

[11] Javier Rios, Johan Karlsson. 2009 "Magallenes - A web services discovery and automatic workflow composition tool”, Journal of BMC Bioinformatics, pp. 334-346.

[12] Stefan Dietze, John Domingue et al. 2010 "An automated approach to Semantic Web Services Mediation", Springer Verlag SOCA, pp. 261-275.

[13] Ermolayev V., N. Keberle et al. 2007 "Towards a Framework for Agent Enabled Semantic Web Service Composition", International journal of Web Services Research, pp. 63-87.

[14] Sandeep Kumar and R.B. Mishra. 2008 “ Semantic web service composition", IETE Technical Review, pp. 105121.

[15] P Kungas and M Matskin.2006 "Semantic web service composition through a P2P based multi agent environment", lecture notes in computer science, $\mathrm{pp}$. 4118.

[16] V. Portchelvi, V Prasanna. 2012 "Achieving web service composition - a survey",International journal of software engineering, pp. 195-202.

[17] Yasmine Charif and Nicolas Sabouret. 2006 "An Overview of semantic web service composition approaches, Elsevier electronic notes in computer science, pp. 33-41.

[18] Aditya Khamparia and Babita Pandey. 2013 "Review on Semantic Web Service Processes", $2^{\text {nd }}$ International conference on computing science, Elsevier Indexed, pp. 387-392.

[19] Aditya Khamparia and Babita Pandey. 2014 "An ontology driven multi-agent approach for diabetes management", international multitrack conference on science energy and innovations, pp. 257-259. 